\begin{abstract}
"Mircea cel Batran" Naval Academy Scientific Bulletin, Volume XX - 2017 - Issue 1
The journal is indexed in: PROQUEST / DOAJ / Crossref / EBSCOhost / INDEX COPERNICUS / DRJI / OAJI I

JOURNAL INDEX I I2OR / SCIENCE LIBRARY INDEX / Google Scholar / Academic Keys/ ROAD Open Access I Academic Resources / Scientific Indexing Services / SCIPIO / JIFACTOR
\end{abstract}

\title{
REAL SHOOTING TRAINING TARGET AUTOMATED WITH ARDUINO
}

\author{
Nicolae BADARA ${ }^{1}$ \\ Ovidiu CRISTEA ${ }^{2}$ \\ Paul BURLACU ${ }^{3}$ \\ Tiberiu PAZARA ${ }^{4}$ \\ Mihai BALACEANU ${ }^{5}$ \\ Florentiu DELIU ${ }^{6}$ \\ 1" Mircea cel Batran" Naval Academy, Constanta, Romania, IEEN Department \\ ${ }^{2}$ Lecturer Lecturer "Mircea cel Batran" Naval Academy, Constanta, Romania \\ ${ }^{3}$ Associate professor "Mircea cel Batran" Naval Academy, Constanta, Romania \\ ${ }^{4}$ Lecturer "Mircea cel Batran" Naval Academy, Constanta, Romania \\ ${ }^{5}$ Eng PhD student "Mircea cel Batran" Naval Academy, Constanta, Romania \\ ${ }^{6}$ Associate professor "Mircea cel Batran" Naval Academy, Constanta, Romania
}

\begin{abstract}
The Word is facing with tremendous changes in the geopolitical relationship, which act like a cold war and put pressure on anybody, especially on military personnel. Also, there are new types of asymmetrical conflicts which includes terrorist acts. As the entire Word is changing and the threats are evolving, is necessary to improve the training facilities for military personnel. This paper propose a method to update a low caliber munition shooting training target using microprocessor's processing and vibration sensors. The main idea is to create a sophisticate training battle field for military personnel. All the target will have capabilities to act by them-self, or coordinated by the instructor. The paper present the automated part of the entire project. In order to achieve that we used a simple Arduino One board, a vibration sensor and a step-by-step electrical motor with its driver.
\end{abstract}

Key words: Arduino, automated target, stepper motor, vibration sensor

\section{INTRODUCTION}

During the last years the world have been changing tremendous from all point of view. It is a fantastic mixt between continuous technology development, in very fast rate, big data sharing, from every corner of the Earth, and population migrations. Also, the world is facing terrorism which take advantages of all the facts presented above. In this context, we strongly believe that is mandatory for everybody to help humankind to keep its safety and conscience. It is important to improve the defense technologies in all fields.

Our article started from the need of developing a new type of low caliber shooting target, which can be integrated in a modern training battle field. So, we didn't have an innovation idea, we had a problem to solve and after that we developed the idea. We developed an automated and remote controlled shooting target, using the classical cartoon target and automation based on Arduino parts.

At a first view the project is simple, but because of the rigorous aspects of the shooting training, it consumes a lot of time and resources, despite the desire of a low production cost. After we had some solutions for this problem we received a new challenged - monitoring the shooting process.

The article contains a proposed method of an automated shooting target integrated in a modern shooting range, components and connections, programming code, experiments discussions, future perspective of development and conclusions.

PROJECT DETAILS

The big project which contains our subproject is about developing a modern small caliber gun shooting training field for military personnel. This one should offer a training assisted by the computer and supervised by shooting instructor. That is why the system must have automated targets which can follow a strategy previous developed and recorded by shooting experts. Another facility required is that the system must offer real time shooting visual monitoring. All these equipment must be deployed in different strategical location. Also, the system must have modular parts for flexibility in configuration and ease of installation. All modules must be watertight, waterproof and shockproof.

The automated targets must feel the bullets and, based on what the instructor wants, they can counter the hits or they can turn 90 degrees from the shooting line to simulate the collapse of the target. The target must automatic reappear after a selected period of time or after the instructor signal. The rotation and fix position operations must be realized even in strong wind situations. Every target must have video surveillance with day and night vision.

Our proposed target uses a stepper motor, an Arduino Uno, a driver and a DC source. We have chosen Arduino because is an open source project with a high popularity in academic domain, offering many good scientific examples[1]-[3] from 


\section{"Mircea cel Batran" Naval Academy Scientific Bulletin, Volume XX - 2017 - Issue 1 The journal is indexed in: PROQUEST / DOAJ / Crossref / EBSCOhost / INDEX COPERNICUS / DRJI / OAJI I JOURNAL INDEX I I2OR / SCIENCE LIBRARY INDEX / Google Scholar / Academic Keys/ ROAD Open Access I Academic Resources / Scientific Indexing Services / SCIPIO / JIFACTOR}

a large variety of sensors and actuators with experimental results.

\section{ARDUINO UNO}

"The Arduino Uno is a microcontroller board based on the ATmega328. It has 14 digital input/output pins, and six of them can be used as Pulse Width Modulation (PWM) outputs. Furthermore, it is provided with six analog inputs, a 16-MHz crystal oscillator, a USB connection, a power jack and an In Circuit Serial Programming header. The Arduino Uno can be powered via USB connection or with an external power supply (i.e., a $9-\mathrm{V}$ battery). The power source is selected automatically. The board can operate on an external supply of 6 to 20 volts. The ATmega328 has $32 \mathrm{~KB}$ (with $0.5 \mathrm{~KB}$ used for the bootloader). It also has $2 \mathrm{~KB}$ of SRAM and $1 \mathrm{~KB}$ of EEPROM (which can be read and written with the EEPROM library)" [3].

\section{PROPOSED AUTOMATED TARGET}

The system configuration and connections are defined exactly in the Figure 1. As we mentioned earlier, the system uses a stepper motor for turning the target with 90 degrees counterclockwise and clockwise.This motor is powered by a driver, which is connected to a DC power source and commanded by an Arduino Uno board.

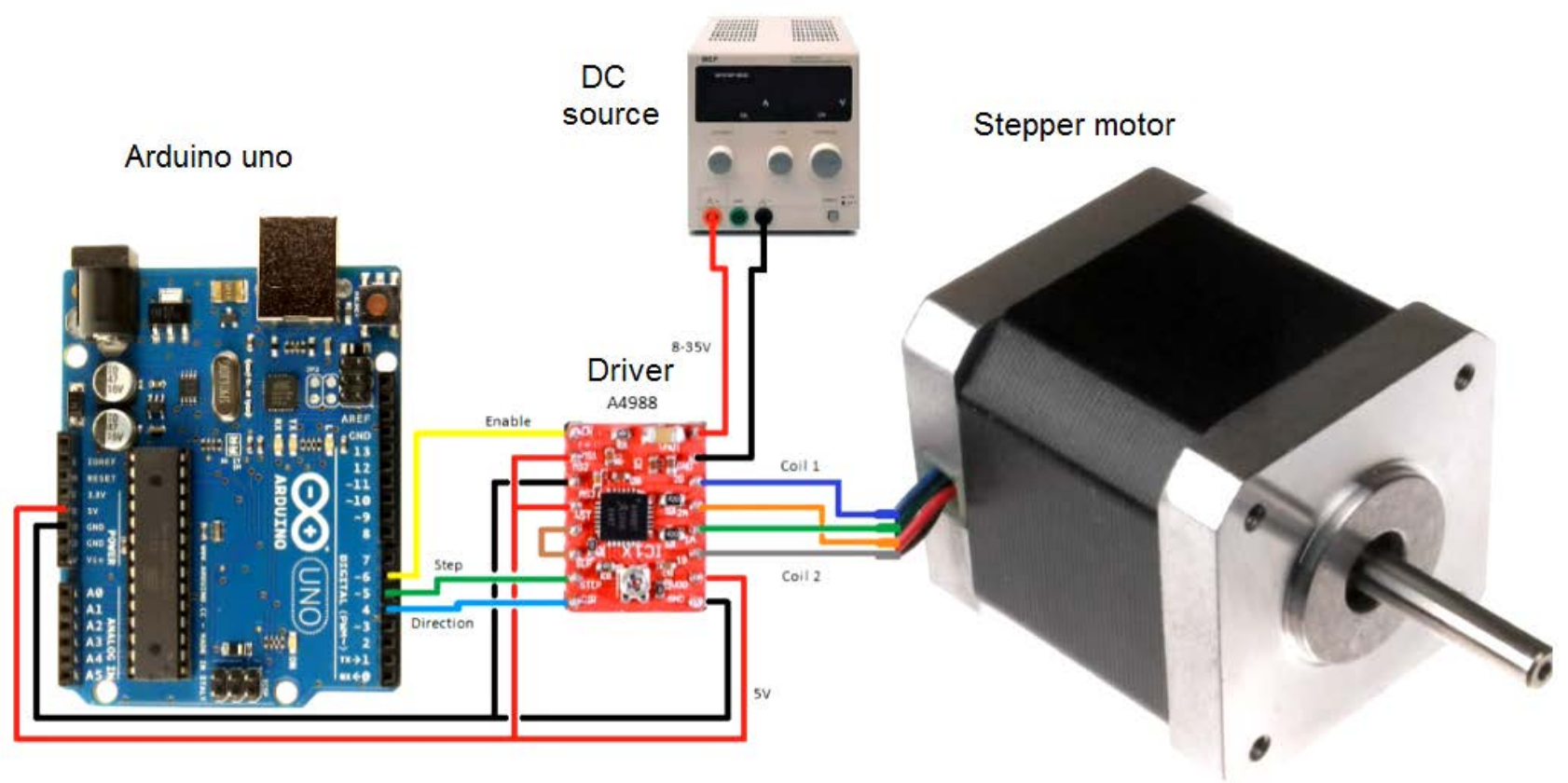

Figure 1 Connection diagram of target automated system without vibration sensor

\section{PROGRAMMING COD}

The actual version of the programming code, listed below, is the result of the laboratory experiments of the automated system and bibliographic research[4]-[9]. After each sentence one can find the comments after the "/l" characters. We encountered serious problems with the driver which proved to generate to much heat for continuous powering the stepper motor. For this reason we modified the code in order to enable the driver only in the moment when the vibration sensor sends a triggering signal via Arduino for turning the target. In this way we solved the thermal losses of the driver but we needed to put an additional mechanism for locking the target in a fix position after 90 degrees rotation. In the future the code will contain a sequence for commanding a device which will offer a powerful and efficient mechanism for keeping the target in a fix position. We provided the full text of code in order to develop and encourage the idea of open source programming.
intvibratie=A0;

intvalvibratie;

int Index;

void setup() \{

pinMode(6, OUTPUT);

pinMode(5, OUTPUT);

pinMode(4, OUTPUT);

digitalWrite $(6, \mathrm{HIGH})$;

Serial.begin(9600);
I/pin AO is now called vibratie which is an integer

/ldefines valvibratie as integer

//defines Index as integer
/IEnable pin

/IStep pin

I/Direction pin

I/Enable ON 


\section{"Mircea cel Batran" Naval Academy Scientific Bulletin, Volume XX - 2017 - Issue 1 \\ The journal is indexed in: PROQUEST / DOAJ / Crossref / EBSCOhost / INDEX COPERNICUS / DRJI / OAJI I JOURNAL INDEX I I2OR / SCIENCE LIBRARY INDEX / Google Scholar / Academic Keys/ ROAD Open Access I Academic Resources / Scientific Indexing Services / SCIPIO / JIFACTOR}

\}

void $\operatorname{loop}()\{$

digitalWrite $(4, \mathrm{HIGH})$;

valvibratie=analogRead(vibratie);

Serial.println(valvibratie);

if (valvibratie> 30) \{

for(Index = 0; Index < 100; Index++)

\{

digitalWrite(6,LOW);

digitalWrite $(5, \mathrm{HIGH})$;

delayMicroseconds(500);

digitalWrite(5,LOW);

delayMicroseconds(500);

digitalWrite $(6, \mathrm{HIGH})$;

\}

delay(30000);

digitalWrite(4,LOW);

for(Index = 0; Index < 100; Index++)

\{

digitalWrite $(6, \mathrm{LOW})$;

digitalWrite(5,HIGH);

delayMicroseconds(500);

digitalWrite(5,LOW):

delayMicroseconds(500);

digitalWrite $(6, \mathrm{HIGH})$;

\}

digitalWrite $(6, \mathrm{HIGH})$;

\}

//Counterclockwise direction

I/valvibratie reads analog value for vibration sensor

IIPrints valvibratie

//the vibration value limit condition

//90 degrees motor counterclockwise rotation

I/Enables the motor driver

I/Rotate sequence

//Rotate sequence

//Rotate sequence

I/Rotate sequence

//Disables the motor driver

I/Waits 30 seconds

//Clockwise direction

//90 degrees motor clockwise rotation

//Enables the motor driver

I/Rotate sequence

//Rotate sequence

//Rotate sequence

I/Rotate sequence

I/Disables the motor driver

I/Disables the motor driver again - safety reasons!

\}

MATHEMATICAL MODEL OF STEPPER MOTOR

Because the stepper motor must be able to turn the target even in a strong wind conditions we studied the mathematical model in order to determine the necessary torque and the current used. There are many mathematical models used for stepper motors [6], [7], [9]-[11], but all of them uses the following system of four non-linear ordinary differential equations:

$$
\begin{aligned}
& \frac{d i_{A}}{d t}=\frac{1}{L} \cdot\left[V_{A}-R \cdot i_{A}+K_{m} \cdot \omega \cdot \sin \left(N_{r} \cdot \theta\right)\right](1) \\
& \frac{d i_{B}}{d t}=\frac{1}{L} \cdot\left[V_{B}-R \cdot i_{B}+K_{m} \cdot \omega \cdot \cos \left(N_{r} \cdot \theta\right)\right](2) \\
& \frac{d \omega}{d t}=\frac{1}{J} \cdot\left[-K_{m} \cdot i_{A} \cdot \sin \left(N_{r} \cdot \theta\right)+\right. \\
& \left.+K_{m} \cdot i_{B} \cdot \cos \left(N_{r} \cdot \theta-B \cdot \omega-\tau_{l}\right)\right](3) \\
& \frac{d \theta}{d t}=\omega(4)
\end{aligned}
$$

where: $i_{a}, i_{b}$ are intensities and $V_{a}, V_{b}$ are voltages in/across phases $\mathrm{A}$ and $\mathrm{B} ; R, L$ are winding's resistance and inductance, respectively; $K_{m}$ is the motor torque constant, $B$ is viscous friction coefficient, $N_{r}$ is the number of rotor teeth, $J$ is rotor's moment of inertia, $\tau$ / is the load torque, $\omega$ is the rotor speed and $\Theta$ is its angular position[10]. LABORATORY EXPERIMENTS

Laboratory tests showed that the code works well for this architecture of the system. We did a lot of tests to identify the proper speed rotation of the stepper motor shaft. When we used a normal shooting target without extra forces on it we obtained that the system worked well. The problems appeared when we increased the weight of the target in order to simulate a strong wind. The stepper motor wasn't able to rotate the target. In order to resolve this problem, in the future, we look to improve our system by adding a more powerful stepper motor or a gear box to amplify the torque of the motor. Mean wile,a possible solution is coming from the mathematical model of the stepper motor. This one is to modify the code in order to achieve a smart start of the rotation. The time delays must be bigger at the start of the rotation in comparison with the time delays after the target achieved a kinetic energy as one can see in (3). To realize this we will include in the code a function for variation of the time delay.

Another very important aspect observed during the lab tests is that the driver delivers a current of 1 A for stepper motor, even in the no rotation state. At a voltage nominal voltage of $12 \mathrm{~V}$, the power is $12 \mathrm{~W}$. After only 2 minutes of tests the 


\section{"Mircea cel Batran" Naval Academy Scientific Bulletin, Volume XX - 2017 - Issue 1 The journal is indexed in: PROQUEST I DOAJ / Crossref / EBSCOhost / INDEX COPERNICUS I DRJI / OAJI I JOURNAL INDEX I I2OR / SCIENCE LIBRARY INDEX / Google Scholar / Academic Keys/ ROAD Open Access I Academic Resources / Scientific Indexing Services / SCIPIO / JIFACTOR}

driver has become hot. So we decided to use the stepper motor only for rotating the target, eliminating power consumption during no rotation state. In order to keep the target fix we will use an

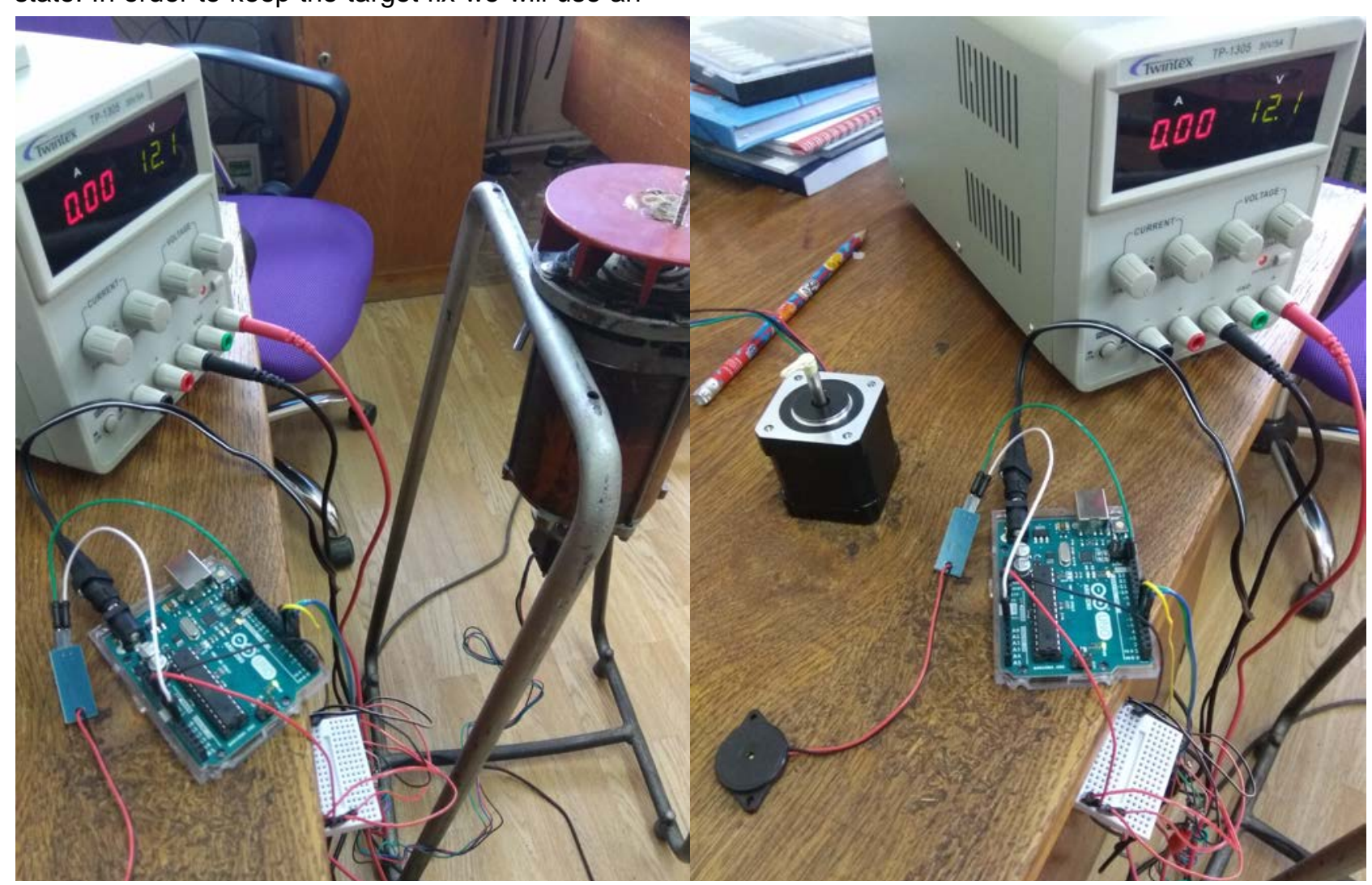

Figure 2 Aspects from laboratory tests with automated target

\section{Conclusion}

The researches' community must start to embrace the idea that the humankind peace, which we live in present, cannot resist forever if we don't help it. It is our duty to align the new technologies to the defense efforts. A very simple example is presented in this research paper.

The idea to have an automated target placed in a modern training battle field is not new, but the solution presented is for sure.

The most important thing demonstrated by this article is that one can use cheap automation developing kits for creating important defense tools, which usually are very expensive.

The problems encountered in the developing process have feasible solutions as were presented.

In the future, the research team will develop this project and we will realize a real automated small caliber shooting target.

\section{Bibliography}

[1] N. S. Kumar, B. Vuayalakshmi, R. J. Prarthana, and A. Shankar, "IOT based smart garbage alert system using Arduino UNO," in 2016 IEEE Region 10 Conference (TENCON), 2016, pp. 1028-1034.

[2] O. H. Graven and J. Bjork, "The use of an Arduino pocket lab to increase motivation in Electrical engineering students for programming," in 2016 IEEE International Conference on Teaching, Assessment, and Learning for Engineering (TALE), 2016, pp. 239-243.

[3] A. D'Ausilio, "Arduino: A low-cost multipurpose lab equipment," Behav. Res. Methods, vol. 44, no. 2, pp. 305-313, Jun. 2012.

[4] S. Banihani, K. Al-Widyan, A. Al-Jarrah, and M. Ababneh, "A genetic algorithm based lookup table approach for optimal stepping sequence of open-loop stepper motor systems," J. Control Theory Appl., vol. 11, no. 1, pp. 35-41, Feb. 2013.

[5] K. G. Adams and M. VanReenen, "A low-cost stepper motor positioning system with minor closedloop control," Int. J. Adv. Manuf. Technol., vol. 10, no. 3, pp. 191-197, May 1995.

[6] P. Acarnley, Stepping Motors: a guide to theory and practice. The Institution of Engineering and 
"Mircea cel Batran" Naval Academy Scientific Bulletin, Volume XX - 2017 - Issue 1

The journal is indexed in: PROQUEST / DOAJ / Crossref / EBSCOhost / INDEX COPERNICUS / DRJI / OAJI I

JOURNAL INDEX I I2OR / SCIENCE LIBRARY INDEX / Google Scholar / Academic Keys/ ROAD Open Access I Academic Resources / Scientific Indexing Services / SCIPIO / JIFACTOR

Technology, Michael Faraday House, Six Hills Way, Stevenage SG1 2AY, UK: IET, 2002.

[7] G. Mihalache, G. Livint, V. Horga, and A. Arcire, "A new mathematical model for the command sequence generator of a two-phase hybrid stepper motor," in 2016 International Conference and Exposition on Electrical and Power Engineering (EPE), 2016, pp. 640-643.

[8] M. Bendjedia, Y. Ait-Amirat, B. Walther, and A. Berthon, "Position Control of a Sensorless Stepper Motor," IEEE Trans. Power Electron., vol. 27, no. 2, pp. 578-587, Feb. 2012.

[9] M. Butcher, A. Masi, R. Picatoste, and A. Giustiniani, "Hybrid Stepper Motor Electrical Model Extensions for Use in Intelligent Drives," IEEE Trans. Ind. Electron., vol. 61, no. 2, pp. 917-929, Feb. 2014.

[10] R. Kępiński, J. Awrejcewicz, and D. Lewandowski, "Dynamical simulation of a nonlinear stepper motor system," Int. J. Dyn. Control, vol. 3, no. 1, pp. 31-35, Mar. 2015.

[11] D. Samokhvalov, S. Stoliarov, and A. Kekkonen, "The hybrid stepper motor modeling in simulink," in 2015 IEEE NW Russia Young Researchers in Electrical and Electronic Engineering Conference (EIConRusNW), 2015, pp. 282-285. 